\title{
Effect of $\alpha_{2}$-Adrenergic Receptor Antagonist (Midaglizole) on Gastrointestinal Motility in Conscious Dogs
}

\author{
Kazumoto, Fujir*, Masazumi, OKajIma**, Katsufumi, Kawahori**, \\ Yoshiko, MuraKami*** and Tomohiko, Shimatani* \\ Department of Physiology*, Surgery** and Internal Medicine***, School of \\ Medicine, Hiroshima University
}

\begin{abstract}
Fujii, K., Okajima, M., Kawahori, K., Murakami, Y. and Shimatani, T. Effect of $\alpha_{2}$ adrenergic receptor antagonist (Midaglizole) on gastrointestinal motility in conscious dogs. Jpn. J. Smooth Muscle Res., 1989, 25 (4), 000-000, 1989 — To clarify the physiological role of the mechanism that adrenergic nerve inhibits Ach release from intramural cholinergic nerve endings, the influence of Midaglizole, $\alpha_{2}$-adrenergic receptor antagonist, to postprandial gastrointestinal motilities in conscious dogs was investigated.

Postprandial motilities of gastric antrum, duodenum, ileum, and colon were significantly enhanced by Midaglizole (3.0-5.0 $\mathrm{mg} / \mathrm{kg}$ body weight, i.v.). These excitatory responses were abolished by atropine $(0.05-0.1 \mathrm{mg} / \mathrm{kg}$ body weight, i.v.). On the other hand, in most cases (29 cases out of 32 ), when Midaglizole was administered during quiesent phase of IMC, no change occurred in gastrointestinal motility. However, after subliminal dose of pentagastrin or cisapride, which stimulated Ach release from intramural cholinergic neuron without development of motility, was administered, Midaglizole induced phasic, postprandial motility-like contraction in gastrointestinal tract. Even in the fasted state, when Midaglizole was administered intragastrically, irregular contractions with high amplitude occurred in every regions from gastric antrum to colon. And these excitatory responses were abolished by atropine. Similar reaction was observed also in truncal vagotomized dogs.

These results suggest that it is the physiological mechanism that adrenergic nerve presynaptically inhibits Ach release from intramural cholinergic neuron, which is the main mechanism of development of postprandial motility, acting on $\alpha_{2}$-adrenergic receptor, and has tonic control of postprandial motility.
\end{abstract}

Key Words : Midaglizole, $\alpha_{2}$-adrenergic receptor antagonist, Interdigestive migrating contraction (IMC), Postprandial motility

\section{Introduction}

It is well known that adrenergic nerve inhibits gastrointestinal motility. One of the

Accepted for publication, December 25, 1989

藤井一元, 島谷智彦: 広島大学医学部第二生理学教室

岡島正純, 川堀勝史: 広島大学医学部第二外科学教室

村上祥子：広島大学医学部第一内科学教室 
mechanisms associating with this inhibition is described below which has already been proved in vitro, noradrenaline, which is released from the adrenergic postganglionic nerve endings, acts on $\alpha_{2}$-adrenergic receptor of intramural cholinergic nerve which leads to the inhibition of EPSP (Nishi and North, 1973 ; Hirst and Mckirdy, 1974) and Ach release (Lipshutz et al, 1972; Vizi et al, 1973).

However, there is little information on the physiological role of this mechanism or on its relation to the regulatory action of gastrointestinal motility. Therefore, in order to examine the physiological role of the mechanism in which adrenergic nerve inhibits Ach release from the intramural cholinergic nerve, we investigated postprandial gastrointestinal motility in a dog model.

Postprandial gastrointestinal motility is mainly exhibited by the reaction in which gastrin, released by the chemical stimulation of gastric contents, stimulates Ach release from intramural cholinergic nerve (Fujii et al., 1986).

On the other hand, endogenous gastrin releases histamine (Fujii et al., 1981) which stimulates the smooth muscle (Fujii et al., 1986). This reaction is also partially involved in the process of postprandial gastrointestinal motility.

The latter reaction can be removed by cepharanthine (Fujii et al., 1981), an inhibitor of histamine release from histamine secretory cells in the gastrointestinal wall, or by histamine $\mathrm{H}_{1}$-receptor antagonists (Fujii et al., 1981). Consequently, using these blocking agents, postprandial gastrointestinal motility can be produced dolely by the former reaction.

Therefore, by studying the effect of $\alpha_{2}$-adrenergic receptor antagonist on postprandial gastrointestinal motility, the physiological role of the above mechanism can be indicated.

In this study, Midaglizole (Yamanaka et al., 1984), an $\alpha_{2}$-adrenergic receptor antagonist, was administered to dogs after feeding or under fasted state (quiescent phase of interdigestive migrating contraction, IMC), and its effect on gastrointestinal motility was compared.

\section{Methods}

Nine adult mongrel dogs, weighting $10-15 \mathrm{~kg}$, were used. Under pentobarbital sodium anesthesia (Nembutal, Abbott; intravenous injection of $25 \mathrm{mg} / \mathrm{kg}$ body weight), strain gauge force transducer (Star Medical, Japan, F-12IS) was sutured on to the serosal surface of various regions of the gastrointestinal tract (pyloric antrum, duodenum, distal ileum, proximal and distal colon) so that the contractile activity of the circular muscle can be recorded. Transducer lead wires, taken from the abdominal cavity via subcutis to the middle region of the superior end of bilateral shoulder blade, were fixed. They were connected to the amplifier (Star Medical, Japan, FS-02) and recorder (Graphtec, Japan, WR-3701) during experiment, and gastrointestinal motility was recorded under conscious state without restraint. On the other hand, gastrointestinal contractile signals from the amplifier were integrated (Nihon Koden, Japan, EI-601G) and also recorded. In some dogs, gastric canulla was located at the greater curvature of the border of gastric body and pyloric antrum in order to administer the drug directly into the gastric cavity.

Experiments were taken place when normal IMC was confirmed after 7-10 days of operation. 


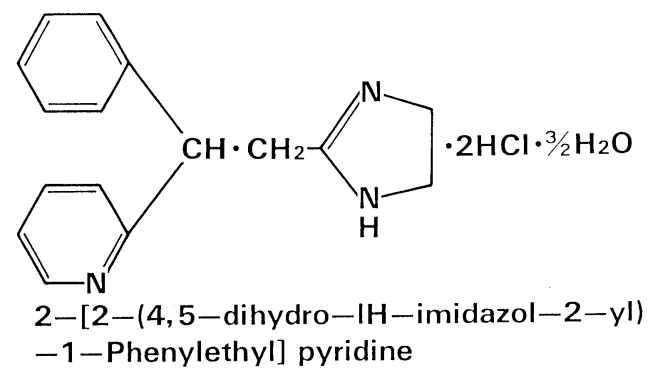

Fig. 1 Structure of 2-[2-(4,5-dihydro-1H-imidazole-2-yl)-1-phenylethyl] pyridine (Midaglizole)
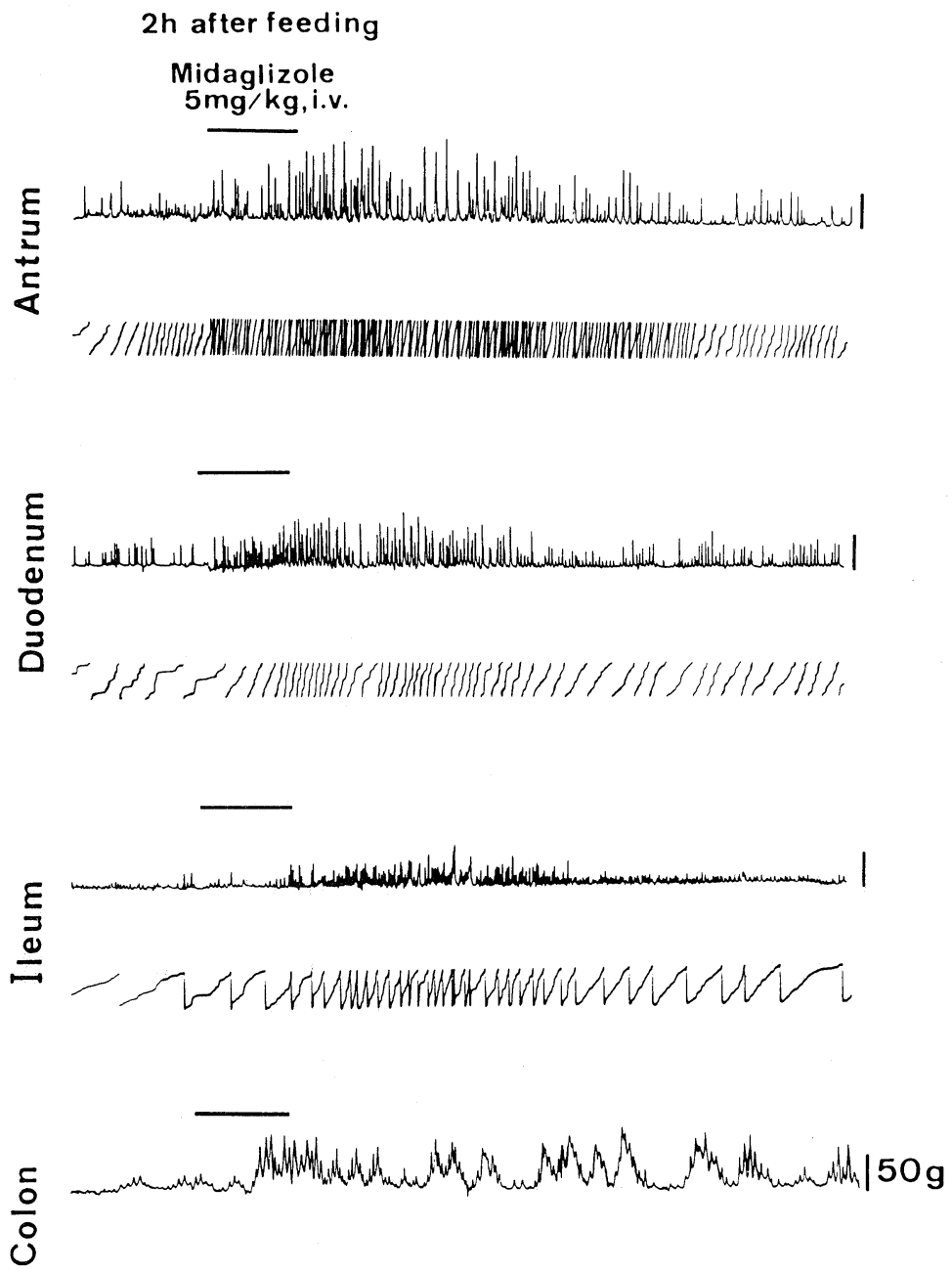

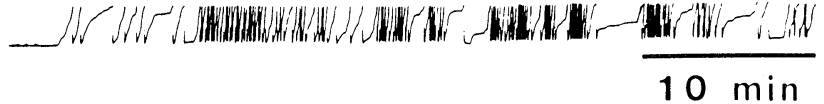

Fig. 2 Excitatory response of postprandial motilities of gastrointestinal tract caused by intravenous administration of Midaglizole.

Upper: Gastrointestinal motility.

Lower: Integral curve of gastrointestinal motility. 
Pelleted dog diet (150 g, Nihon Clea, Japan, CD-5) was mixed with bread gruel (bread $500 \mathrm{~g}$ boiled with $200 \mathrm{cc}$ of water, and $25 \mathrm{~g}$ of powder skim milk was added), and given regularly once daily (approximately $600 \mathrm{Cal}$ ). Same diet was also given during the experiment.

The following agents were used in this study: Midaglizole (Daiichi Seiyaku, Japan, Fig. 1), atropine sulfate (Tanabe Seiyaku, Japan), pentagastrin (Sumitomo Seiyaku, Japan) and dchlorpheniramine maleate (d-CPM, Shionogi Seiyaku, Japan.). Midaglizole was dissolved with physiological saline $5 \mathrm{ml}$, and administered from the cephalic vein using infusion pump $(1.0 \mathrm{ml} /$ min; Tokyo Rika, Japan, MP-3). In some dogs, Midaglizole, wrapped with wafer, was administered directly into gastric cavity via gastric canulla. Pentagastrin and d-CPM were administered subcutaneously while atropine sulfate was administered from the cephalic vein by rapid injection.

\section{Results}

1. Excitatory response of postprandial gastrointestinal motility caused by intravenous administration of Midaglizole.

Postprandial gastrointestinal motility was enhanced by Midaglizole $(5.0 \mathrm{mg} / \mathrm{kg}$ body weight, i.v.) when administered during the digestive state, at 2 hour after feeding (Fig. 2).
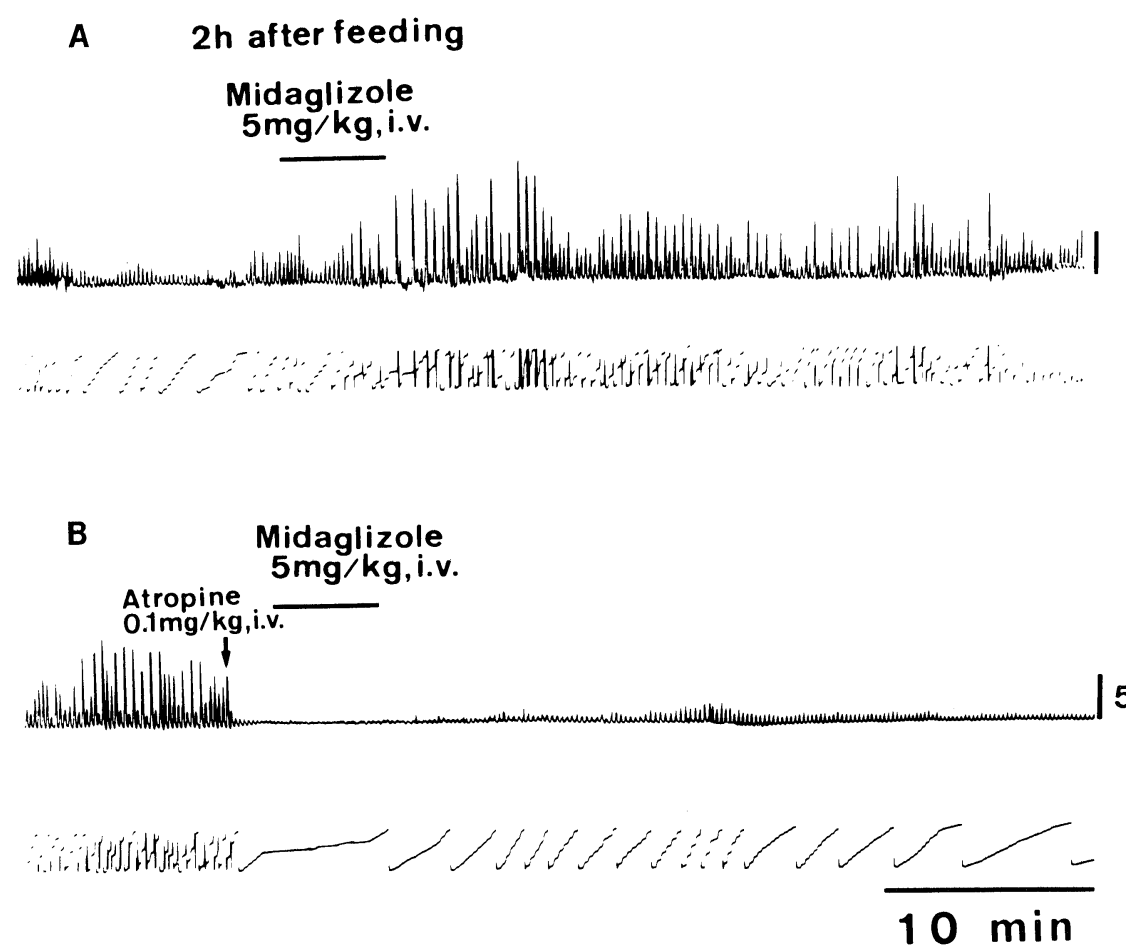

Fig. 3 Effect of atropine on excitatory response of postprandial gastric motility caused by Midaglizole.

A : Excitatory effect of Midaglizole on postprandial gastric motility.

B : Effect of atropine on Midaglizole-induced excitatory response of postprandial gastric motility.

Upper: Gastric motility.

Lower: Integral curve of gastric motility. 
Postprandial motility of pyloric antrum, duodenum, distal ileum and proximal colon were all enhanced by Midaglizole, and amplitude and frequency of contraction were significantly increased. Similar reaction was also observed in truncal vagotomized dogs (TV dog, Fig. 2 ileum).

This enhancement effect of Midaglizole (i.v.) was observed at doses of 1.0, 1.5, 1.8, 2.0, 2.5, 3.0 and $5.0 \mathrm{mg} / \mathrm{kg}$ body weight. When the dose was $2.5 \mathrm{mg} / \mathrm{kg}$ or less, however, the effect was inconstant even in the same individual, and dose dependency was not seen. Maximum enhancement effect was observed at doses of $3.0 \mathrm{mg} / \mathrm{kg}$ or more.

2. Effect of atropine on the excitatory response of postprandial motility caused by Midaglizole.

Fig. 3A shows the postprandial gastric motility enhanced by Midaglizole $(5.0 \mathrm{mg} / \mathrm{kg}$ body weight, i.v.). When atropine ( $0.1 \mathrm{mg} / \mathrm{kg}$ i.v.) was administered during this reaction, the motility was dramatically inhibited (Fig. 3B). Remarkable enhancement observed in control (Fig. 3A) was not seen when Midaglizole was administered under the effect of atropine. A very weak rhythmic contraction, however, was observed from 2 minutes after Midaglizole administration. This weak contraction disappeared when the animal was pre-treated with d-CPM $(2.5 \mathrm{mg} / \mathrm{kg}$, s.c.).

In TV dogs, postprandial motility of distal ileum was enhanced by Midaglizole $(5.0 \mathrm{mg} / \mathrm{kg}$

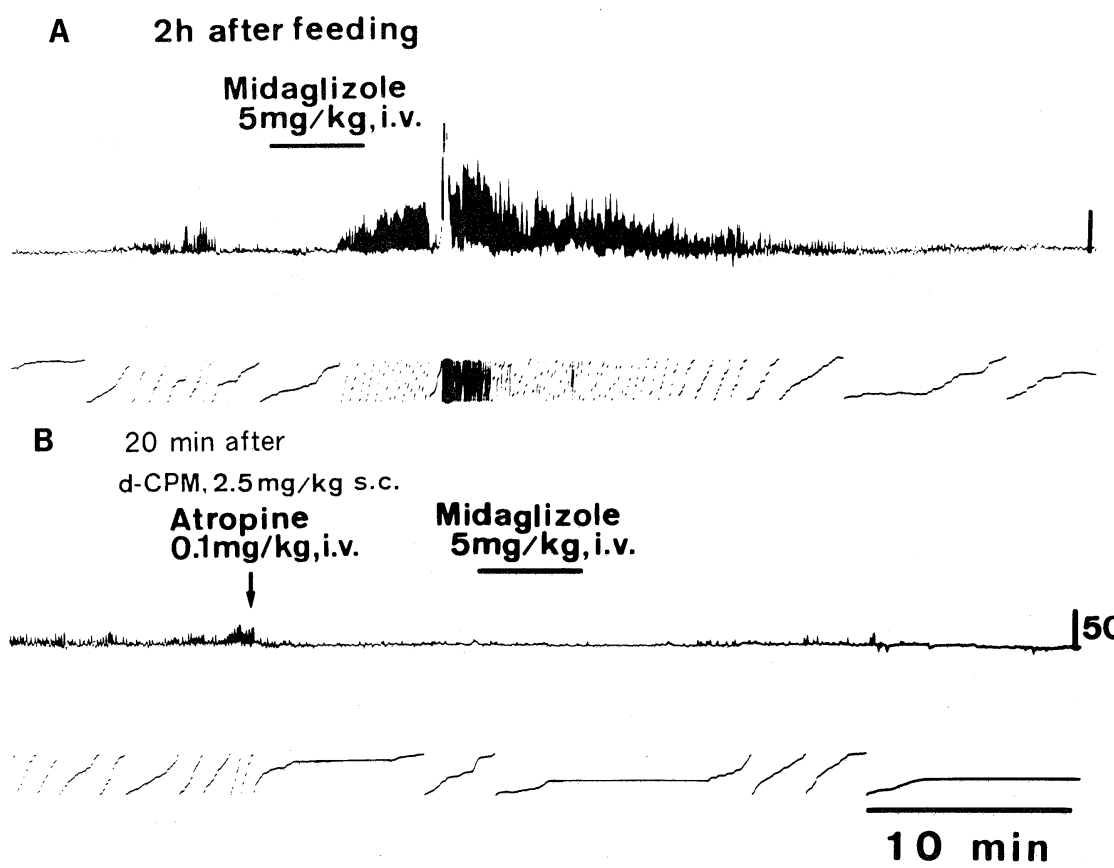

Fig. 4 Inhibitory effect of atropine and d-CPM on Midaglizole-induced excitatory response of postprandial ileal motility in truncal vagotomized dog.

A : Midaglizole-induced excitatory response of postprandial ileal motility.

$\mathrm{B}$ : Inhibitory effects of atropine and $\mathrm{d}-\mathrm{CPM}$ on Midaglizole-induced excitatory response of postprandial ileal motility.

Upper : Ileal motility.

Lower: Integral curve of ileal motility. 


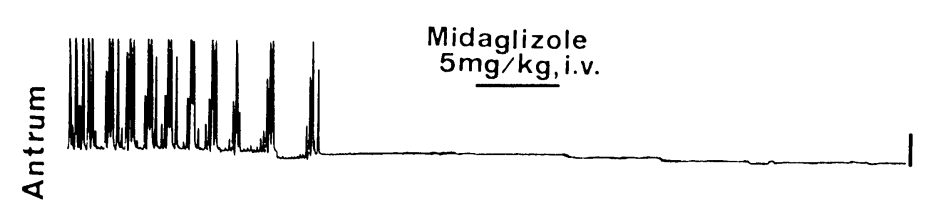

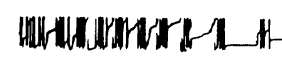
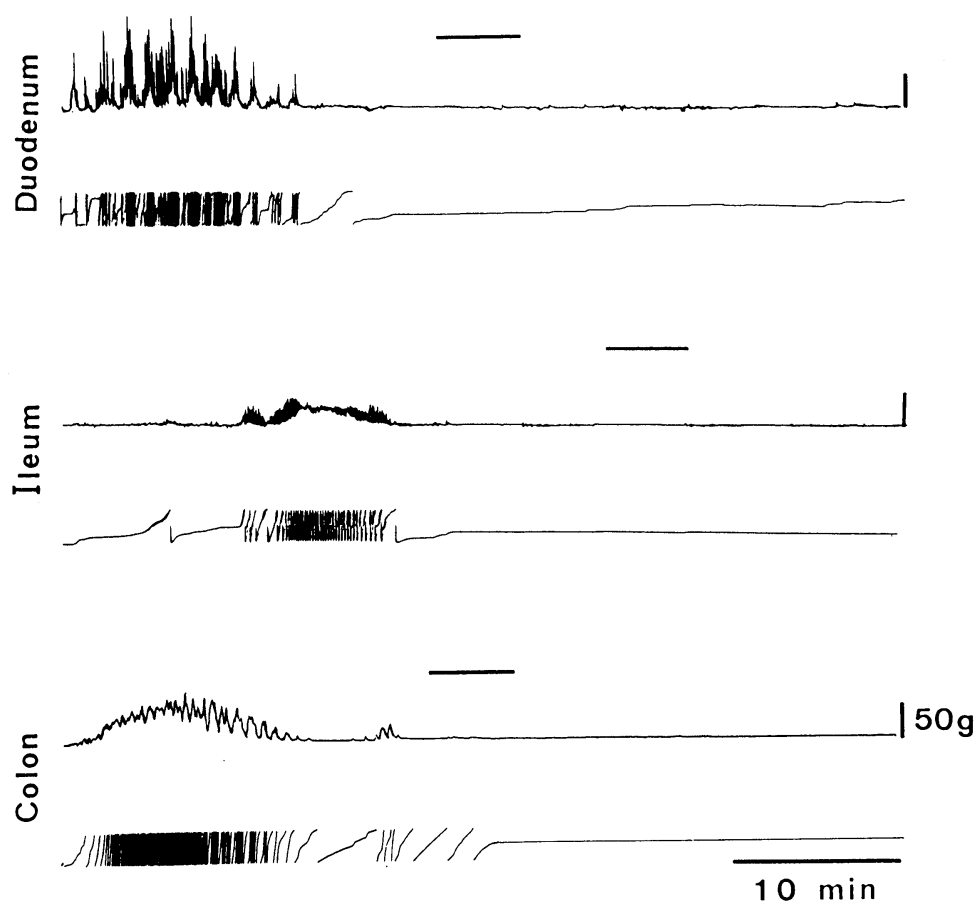

Fig. 5 Effect of Midaglizole on gastrointestinal motilities when administered intravenously during the quiescent phase of IMC.

Upper: Gastrointestinal motilities.

Lower: Integral curve of gastrointestinal motilities

body weight, i.v., Fig. 4A), while this reaction was not observed under the effect of d-CPM and atropine (Fig. 4B).

The inhibitory effect of atropine or d-CPM observed in stomach (Fig. 3) and ileum (Fig. 4) was also observed in the other regions of the gastrointestinal tract.

3. Effect of Midaglizole on gastrointestinal motility when administered intravenously under fasted state.

When Midaglizole was administered during the quiescent phase of IMC in stomach, duodenum, distal ileum and distal colon, no contractions were induced in any of the regions with exceptions in some cases ( 3 out of 32 cases studied).

Thus, Midaglizole (i.v.) enhanced the gastrointestinal motility when administered after feeding (Fig. 2), while no reaction was observed when administered under fasted state (Fig. 5). In order to investigate the mechanism of this phenomenon, Midaglizole was administered (i.v.) 


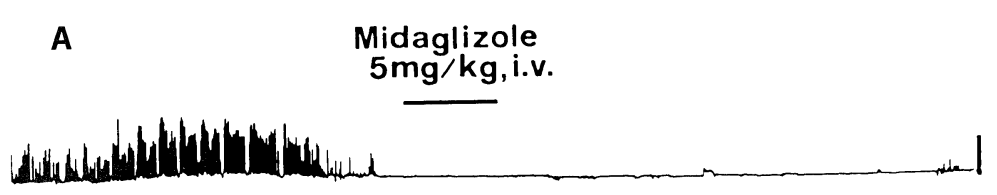

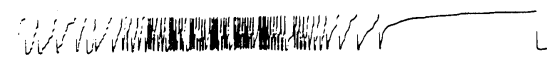

B
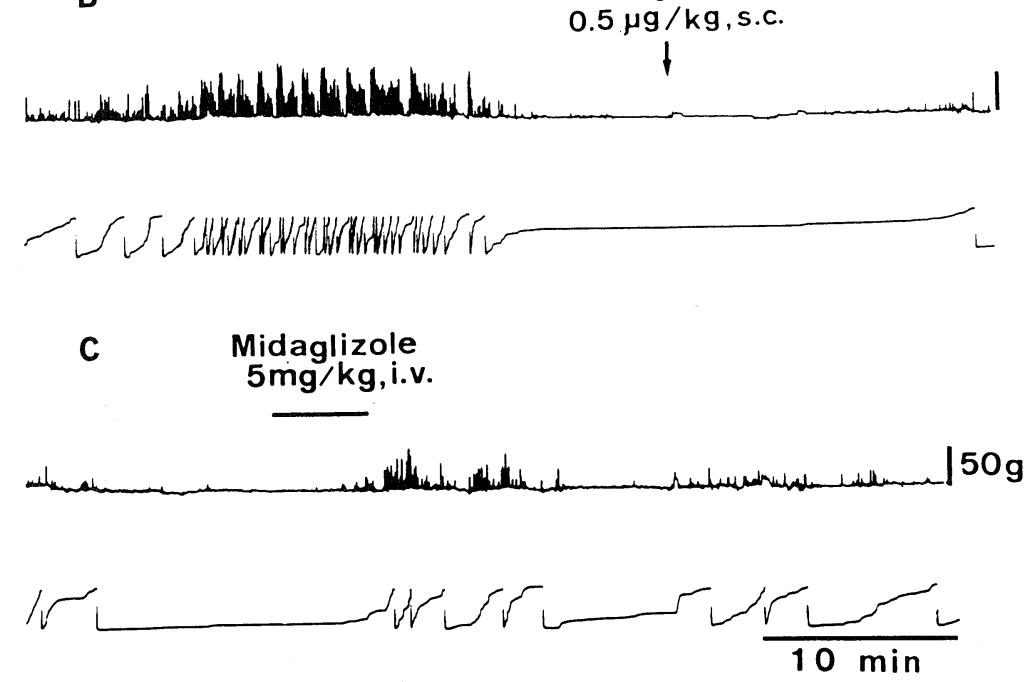

Fig. 6 Effect of Midaglizole on duodenal motility pre-treated with subliminal dose of pentagastrin during the quiescent phase of IMC.
A : Administration of Midaglizole
B : Administration of subliminal dose of pentagastrin.
C: Effect of Midaglizole in the presence of subliminal dose of pentagastrin.
Upper: Duodenal motility.
Lower: Integral curve of duodenal motility.

under the effect of pentagastrin (subliminal dose) and d-CPM, and the duodenal motility was examined.

Fig. 6A shows that Midaglizole $(5.0 \mathrm{mg} / \mathrm{kg}$ body weight, i.v.), when given during the quiescent phase of IMC, had no effect on duodenal motility. Subliminal dose of pentagastrin (in this case, $0.5 \mu \mathrm{g} / \mathrm{kg}$ body weight) was administered under treatment by d-CPM $(2.5 \mathrm{mg} / \mathrm{kg}$ body weight) (Fig. 6B). When Midaglizole was administered intravenously under this condition, rhythmic contraction of duodenum was induced (Fig. 6C).

Further, when the animal was pre-treated with cisapride $(1.0 \mathrm{mg} / \mathrm{kg}$ body weight, i.v.), an Ach releasing stimulator from the intramaral cholinergic nerve endings (Pfeuffer-Friederich $e t$ al., 1984 ; Fujii et al., 1988), Midaglizole ( $5.0 \mathrm{mg} / \mathrm{kg}$ body weight, i.v.) induced the rhythmic contraction under fasted state (Fig. 7B, distal ileum in TV dog). 


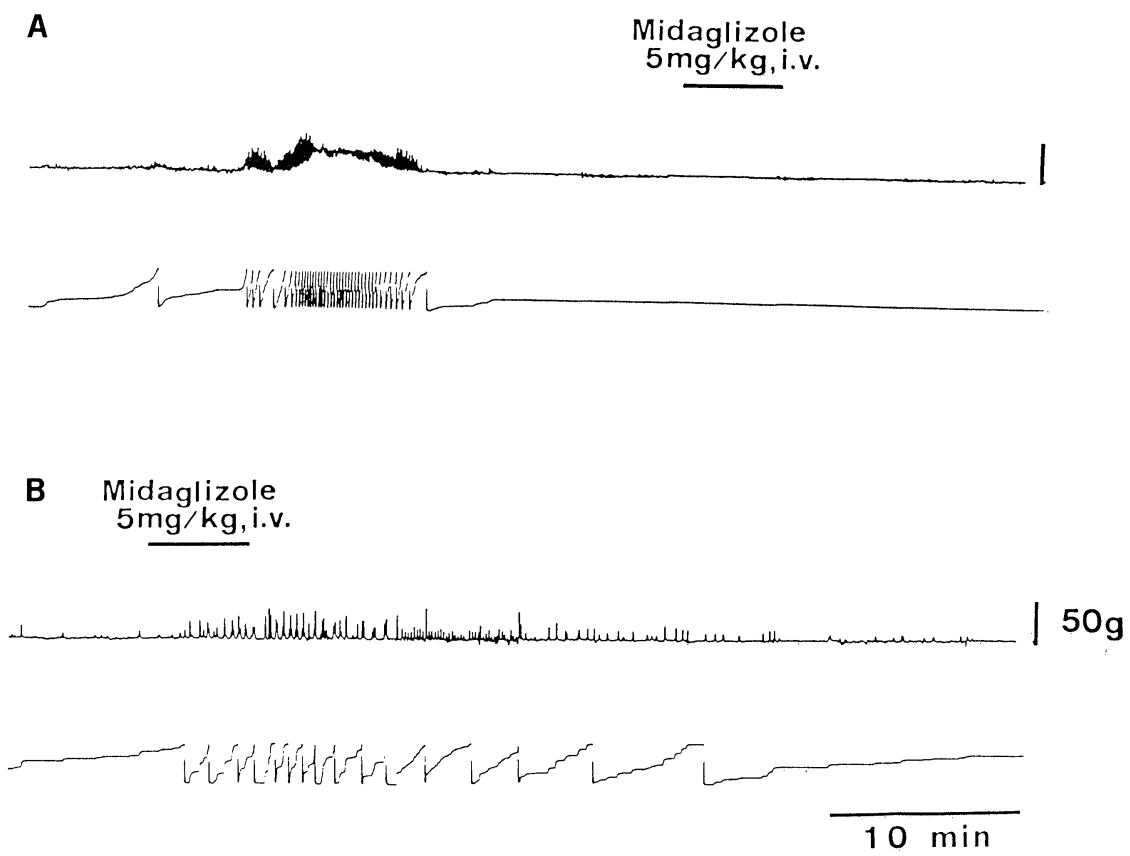

Fig. 7 Effect of Midaglizole on ileal motility pre-treated with cisapride during the quiescent phase of IMC in truncal vagotomized dog.
A : Administration of Midaglizole during the quiescent phase of IMC in ileum.
B : Effect of Midaglizole presence of cisapride.
Upper : Ileal motility.
Lower: Integral curve of ileal motility.

4. Enhancement of gastrointestinal motility under fasted state caused by intragastric administration of Midaglizole.

Midaglizole (20 $\mathrm{mg} / \mathrm{kg}$ body weight), wrapped with wafer, was administered directly into the gastric cavity via gastric canulla. Proximal colon motility of a representative case is shown in Fig. 8.

Contraction, similar to the postprandial reaction, was induced soon after dosing. It turned to mass peristalsis-like activity from 30 minutes after dosing (Fig. 8A, upper chart). This animal showed defecation posture when strong contraction occurred (Fig. 8A, lower chart), and then small amount of mucous stool was excreted (Fig. 8A, lower chart, $\downarrow$ ). The contraction of colon shown in the left side of Fig. $8 \mathrm{~B}$ was induced with Midaglizole $(20 \mathrm{mg} / \mathrm{kg}$ body weight, direct administraction) 2 days after the study of Fig. 8A. As in Fig. 8A, mass peristalsis-like activity was observed. This contraction disappeared by atropine $(0.1 \mathrm{mg} / \mathrm{kg}$ body weight, i.v. $)$ (Fig. 8B).

Midaglizole was administered directly into gastric cavity under fasted state in 8 cases, and all of them showed mass peristalsis-like colon activity, which disappeared by atropine administration. The animal shown in Fig. 8A was the only case which showed defecation posture or defecation.

Stomach, duodenum and ileum also showed IMC-like activity soon after direct administra- 
Midaglizole

$20 \mathrm{mg} / \mathrm{kg}$, int.gast.

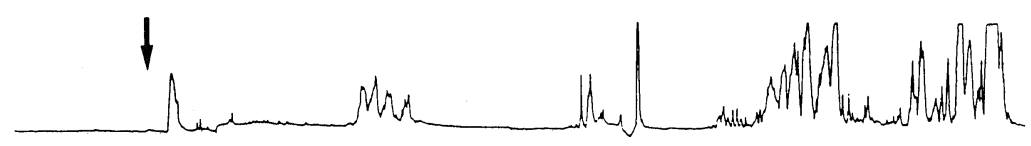

A
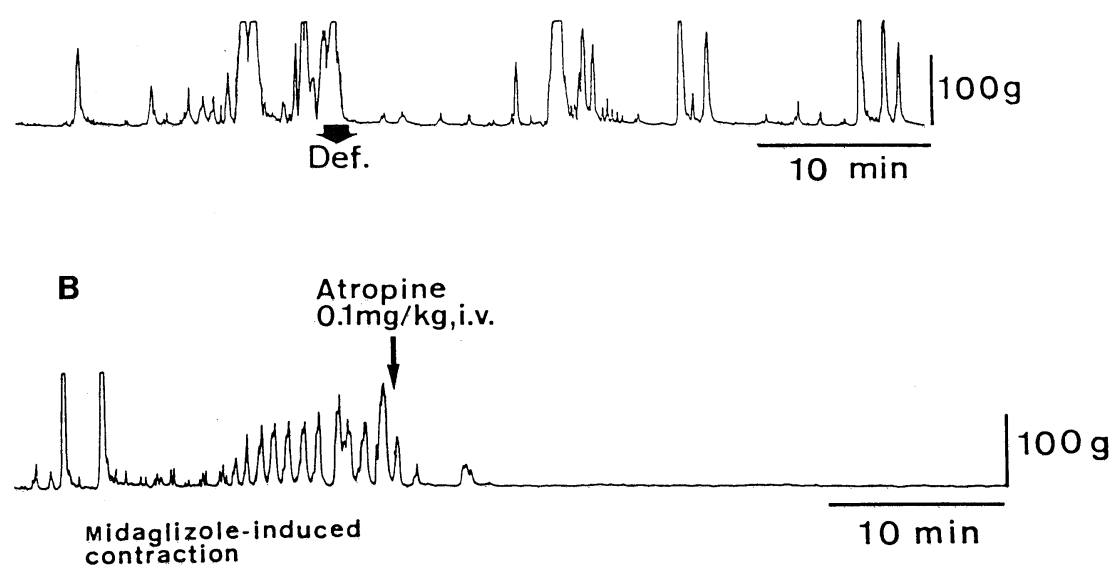

Fig. 8 Enhancement of colonic motility under fasted state caused by intragastric administration of Midaglizole and effect of atropine on this response.

A : Excitatory response of colonic motility (upper and lower chart) caused by Midaglizole.

B : Inhibitory effect of atropine on Midaglizole-induced colonic motility.

tion of Midaglizole under fasted state, and then turned to postprandial-like pattern from 30 minutes after dosing.

\section{Discussion}

In vitro experiments have proved the mechanisms described below in which adrenergic nerve inhibits the gastrointestinal smooth muscle activity: One of the mechanisms is presynaptic inhibition of the cholinergic nerve in the intramural nerve plexus by acting on $\alpha$ adrenergic receptor (Nishi and North, 1973; Hirst and Mckirdy, 1974; Vizi et al., 1973). Consequently, EPSP or Ach release, the activities of cholinergic nerve, are inhibited. And the other is stimulation to the intramural non-adrenergic inhibitory nerve (Gabella and Costa, 1971 ; Nishi and North, 1973).

On the other hand, using conscious dog models, we have been investigating the physiological role of the intramural cholinergic nerve in the developmental mechanism of postprandial gastrointestinal motility (Fujii, 1985; Fujii and Okajima, 1986; Okajima et al., 1987), and reported as follows. Postprandial gastrointestinal motility is mainly exhibited by the reaction in which gastrin, released by chemical stimulation of stomach contents, stimulates Ach release from intramural cholinergic nerve. On the other hand, endogenous gastrin also stimulates histamine release (Fujii et al., 1981) which acts on the gastrointestinal smooth muscle, however, this reaction is only partially involved. 
In this study, intravenous administration of Midaglizole, an $\alpha_{2}$-adrenergic receptor antagonist (Yamanaka et al, 1984, Fig. 1), enhanced the postprandial motility of the whole gastrointestinal tract, from stomach to colon (Fig. 2, Fig. 3A, Fig. 4A). This reaction was inhibited by atropine (Fig. 3B and Fig. 4B). Similar reaction was also observed in TV dogs (Fig. 2 and Fig. 3A). These results were consistent with the reaction induced by intravenous administration of yohimbine or phentolamine (Fujii et al., 1986). The above findings indicate that there is a physiological mechanism in which the intramural cholinergic nerve activity, the main arena of the postprandial motility process, is regulated by adrenergic nerve at the preganglionic site. The existence of this mechanism is supported by the two facts, that increased renal sympathetic nerve activity and plasma noradrenaline level are observed after food intake (Kopin et al, 1978 ; Matsukawa et al., 1986 ; Fujii et al., unpublished).

A weak rhythmic contraction was induced when Midaglizole was administered under the effect of atropine (Fig. 3B) and disappeared by d-CPM (Fig. 4B). It is considered that this weak rhythmic activity was not caused by Midaglizole but by minor reaction of postprandial motility process in which histamine $\mathrm{H}_{1}$-receptor is associated.

Unlike the postprandial effect of intravenous injection of Midaglizole, when given under fasted state, no effect was observed in most cases (29 out of 32 cases studied). This can be explained as follows.

Under fasted state, the excitement level of intramural cholinergic nerve is low because of the reduced blood gastrin level. Consequently, it is supposed that the $\alpha_{2}$-adrenergic receptor antagonizing activities of Midaglizole did not appear. The observation of postprandial-like motility pattern (Fig. 6C and Fig. 7) when animals were pre-treated with pentagastrin (subliminal dose) or whith cisapride, an agent which stimulates Ach release from the intramural cholinergic nerve endings as gastrin (Pfeuffer-Friederich et al., 1984 ; Fujii et al., 1988) will support this speculation.

A mass peristalsis-like activity was induced in the proximal colon when Midaglizole (20 $\mathrm{mg} / \mathrm{kg}$ ) was administered directly into the gastric cavity, via gastric canulla, during the quescent phase of IMC (Fig. 8A). The detailed mechanism in which i.v. dosing induced no effect (Fig. 2, colon) while direct dosing induced mass peristalsis-like activity is unknown. However, from the fact that it disappeared by atropine administration (Fig. 8B), cholinergic nerve might be participated in this reaction.

Midaglizole, by its $\alpha_{2}$-adrenergic receptor antagonizing activity, stimulates insulin release from pancreatic beta-cells in vitro and in vivo (Muramatsu et al., 1983 ; Yamanaka et al., 1984 ; Kawatsu et al., 1987). On the other hand, it is well known that insulin, by lowering blood glucose, stimulates cholinergic fiber in the vagus nerve through the central nervous system, and leads to gastrin secretion and gastrointestinal motility (Fujii and Mukai, 1984). Thus, an assumption arises that insulin might be mediating the enhancement reaction of gastrointestinal motility which was induced by Midaglizole and disappeared with atropine in this study. However, from that fact that Midaglizole also induced gastrointestinal motility enhancement in TV dogs, which was a similar reaction seen in normal dogs, insulin may hardly play a role on its mechanism. 


\section{Acknowledgements}

The authors wish to express our thanks to Daiichi Seiyaku Co., Ltd. who supplied Midaglizole used in this experiment.

\section{References}

Fujii, K., Takasugi, S. and Toki, N. (1981). Effect of cepharanthine on neuro-humoral excitatory responses of gastric movement in dog. Jpn. J. Physiol. 31: 613-623.

Fujii, K. and Mukai, M. (1985). Neurohumoral mechanisms of excitation of gastric motility in the dogs. In: Gastrointestinal Function. Edited by Kasuya, Y. et al., Excerpta Medica, Tokyo, pp. 15-27.

Fujii, K., Mukai, M. and Okajima, M. (1985). Neural and neurohumoral factors participating in postprandial gastric motility. Jpn. J. Smooth Muscle Res. 21 : P. 253-255.

Fujii, K. and Okajima, M. (1986). Effect of atropine, d-chlorphenilamine maleate and DG-5128 on postprandial movements of gastrointestinal tract. J. Physiol. Sci. Japan 48: P. 223.

Fujii, K., Okajima, M. and Kawahori, K. (1986). Effect of $\alpha_{2}$-adrenergic receptor blockade on postprandial gastrointestinal motility. Jpn. J. Smooth Muscle Res. 22 : P. 202-205.

Fujii, K., Okajima, M. and Kawahori, K. (1988). Effect of cisapride on the cholinergic control mechanisms of gastrointestinal motility in dogs. Jpn. J. Smooth Muscle Res. 24 : 1-11.

Gabella, G. and Costa, M. (1968). Adrenergic innervation of the intestinal smooth muscle. Experimentia 25 : 395-396.

Hirst, G.D.S. and Mackirdy, H.C. (1974). Presynaptic inhibition at mammalian peripheral synapse? Nature 250 : 430-431.

Kawazu, S., Suzuki, K., Watanabe, T. and Ishii, J. (1987). Studies of midaglizole (DG-5128), a new type of oral hypoglycemic drug in healthy subjects. Diabetes $36: 216-220$.

Kopin, I.J., Lake, P.C. and Ziegler, M.Z. (1978). Plasma level of norepinephrine. Ann. Int. Med. 88 : $671-680$.

Lipshutz, W. and Choen, S. (1972). Interaction of gastrin I and secretin on gastrointestinal circular muscle. Am. J. Physiol. 222 : 775-781.

Muramatsu, I., Oshita, M. and Yamanaka, K. (1983). Serective alpha-2 blocking action of DG-5128 in the dog mesenteric artery and rat vas deferens. J. Pharmacol. and Experiment. Ther. 227 : 194-198.

Matsukawa, K., Honda, T., Ninomiya, I. and Azumi, T. (1986). Sympathetic control of cardiovascular system at the beginning of eating in awake cats. Autonomic nervous system $23: 374-$ 378.

Nishi, S. and North, A. (1973). Presynaptic action of noradrenaline in the myenteric plexus. $J$. Physiol. 231 : P. 29-30.

Okajima, M., Kawahori, K. and Fujii, K. (1987). Role of the intramural cholinergic neuron in the developmental mechanisms of post-prandial motility. Autonomic nervous system 24: P. 168.

Pfeuffer-friederich, I. and Kilbinger, H. (1984). Facilitation and inhibition by 5-hydroxytriptamine and R51619 of acetylcholine release from guinea-pig myenteric neurons. Proc. 9th Int. Symp. on gastrointestinal motility. Edited by Roman, C., NTP press, Lancaster, pp. 527-534.

Vizi, S.E., Bertaccini, G., Impicciatore, M. et al. (1973). Evidence that acetylcholine released by gastrin and related polypeptides contributes of the effect on gastrointestinal motility. Gastroenterology 64 : 268-277.

Yamanaka, K., Kigoshi, S. and Muramatsu, I. (1984). The selectivity of DG-5128 as $\alpha_{2}$-adrenoceptor antagonist. Eur. J. Pharmacol. 106 : 625-628.

$$
\text { (平成元年 } 3 \text { 月 } 13 \text { 日 受付) }
$$

